\title{
$\begin{array}{llllllll}\boldsymbol{R} & \boldsymbol{a} & \boldsymbol{s} & \boldsymbol{p} & \boldsymbol{r} & \boldsymbol{a} & \boldsymbol{v} & \boldsymbol{e}\end{array}$
}

\section{ZNAČENJE BONAVENTURINE DISTINKCIJE ENTIS ET ESSE}

\author{
Hrvoje Relja
}

Sveučilište u Splitu

UDK: 111.1/.12Bonaventura, sanctus, Thomas Aquines, sanctus Filozofski fakultet Izvorni znanstveni rad* hrelja@ffst.hr Primljeno 05/2018.

\section{Sažetak}

U radu se pokazuje kako je sveti Bonaventura, kao uostalom $i$ svi kršćanski filozofi, adoptirao pojam bitka kako bi na ontološkoj razini objasnio stvorenost stvorenja jer se metafizički uviđa da svako stvoreno biće, ukoliko je stvoreno, nužno prima svoj bitak od Stvoritelja. To posljedično zahtjeva da na osnovnoj ontološkoj razini stvoreno biće bude metafizički sastavljeno od bitka i njemu komplementarnog počela, a što Serafski naučitelj formulira kao sastavljenost od entis et esse. Iako sâm Bonaventura ne daje pobliže tumačenje naravi te navedene sastavljenosti od entis et esse ipak se ona dade, kako je u članku pokazano, deducirati iz njegovih osnounih filozofskih $i$ teoloških teza, koje pretpostavljaju prethodno pojmljenu osnovnu ontološku strukturu bića. Slijedom te dedukcije može se zaključiti da se Bonaventurina sastavljenost od entis et esse ne može interpretirati na način tomističke metafizike bitka, već da ju je plauzibilno shvatiti u sujetlu esencijalističke metafizike, $i$ to kao sastavljenost na transcendentalnoj razini od dvaju realno različitih počela: od bîti, tj. potpuno definiranog/odredenog/individualnog mogućeg bića, te od bitka, čina postojanja realnog konkretnog bića.

Ključne riječi: entis et esse, sv. Bonaventura, bitak, esencijalistička metafizika

\section{UvOD}

Sržno metafizičko pitanje o jednosti i mnoštvenosti ontološkim se razlučivanjem pretvara u pitanje određivanja osnovne ontološke

\footnotetext{
"U tiskanom izdanju članak je pogrješkom vrednovan kao pregledni rad.
} 
strukture bića. U povijesti filozofije različiti modaliteti određivanja osnovne ontološke strukture bića mogu se iskazati kroz pripadajuća im poimanja bitka i bîti te interpretaciju njihova odnosa. ${ }^{1}$ Sveti Bonaventura u svojoj metafizici ne upotrebljava formulaciju distinkcije bitka i bîti, nego ekvivalentu formulaciju distinkcije entis et esse. Sam Serafski naučitelj, kako je razvidno iz sačuvanih mu spisa, ne objašnjava značenje te svoje distinkcije. U ovom ćemo radu pokušati, analizirajući Bonaventurine osnovne filozofske i teološke teze, koje pretpostavljaju prethodno pojmljenu određenu osnovnu ontološku strukturu bića, tj. teze koje su izvedene iz određenog shvaćanja osnovne ontološke strukture bića, deducirati Bonaventurino poimanje osnovne ontološke strukture bića te time i značenje njegove distinkcije entis et esse.

\section{IZVOĐENJE OSNOVNE ONTOLOŠKE STRUKTURE STVORENOG BIĆA}

Promatranje osnovne ontološke strukture stvorenog bića u misli sv. Bonaventure započet ćemo usporedbom načina na koji osnovnu ontološku strukturu stvorenja izvode sv. Bonaventura i sv. Toma.

Oba autora osnovnu ontološku strukturu stvorenog bića izvode iz vlastitosti Božje naravi, koju metafizički poimaju kao apsolutno jedinstvenu. Obojica drže da je Bog Onaj koji Jest; da samo Bog po sebi Jest; da jedino Bogu po sebi pripada Bitak, te da je, stoga, jedino Bog posve jednostavno, nepromjenjivo i savršeno biće, Čisti akt, Čisti bitak; ${ }^{2}$ i da zbog toga sva ostala bića nisu svoj bitak, tj. nemaju u sebi razlog svog postojanja. Dakle, sva ostala bića, ukoliko su bića, budući da nisu čisti akt, da nisu svoj bitak i da ga nemaju po

1 Usp. Étienne Gilson, Bitak $i$ bit, Demetra, Zagreb, 2010., gdje Gilson analizira dominantne pozicije poimanja bitka i bîti u povijesti filozofije. Iako navedena knjiga ne obrađuje poziciju sv. Bonaventure, značajna je za našu temu jer joj daje povijesni okvir.

2 Usp. Bonaventura da Bagnoregio 1 Sent, d. 43, a. unic, q. 3, conc, gdje ističe „Infinitum enim in actu est actus purus, [...] sed quod est actus purus, est suum esse per essentiam." Svi navodi sv. Bonaventure preuzeti su iz Bonaventura da Bagnoregio. Sent. Commentarius in I, II, III, IV librum Sententiarum. U: Doctoris seraphici S. Bonaventurae, Opera omnia; edita studio et cura PP. Collegii a S. Bonaventura ad pl urimos codices mss. emendata, anecdotis aucta, prolegomenis scholiis no tisque illustrata. Tomus I-IV. Ad Claras Aquas (Quaracchi) : Ex Typographia Collegii S. Bonaventurae 1882-1889.; te Toma Akvinski, ST, I, q. 54, a. 1, co., gdje navodi "Solus autem Deus est actus purus.“, i ST, I, q. 4, a. 2, co., gdje naglašava da „Deus sit ipsum esse subsistens.“ Svi navodi sv. Tome Akvinskog preuzeti su iz Toma Akvinski, Opera omnia S. Thomae, http://www. corpusthomisticum.org/iopera.html (08.11.2017). 
sebi, jesu stvorena i zato sastavljena od dva su-počela: akta i potencije te su, prema tome, nužno, kao takva, promjenjiva.

I Serafski i Anđeoski naučitelj primjećuju da se ta nužna sastavljenost stvorenja od metafizičkih su-počela, akta i potencije, daje i na razini djelovanja i na razini bivstvovanja. ${ }^{3} \mathrm{O}$ sastavljenosti na razini djelovanja obojica isto zaključuju, slijedeći ovu argumentaciju: budući da nijedno od stvorenja nije Čisti akt, nužno slijedi da nijedno od stvorenja nije ni svoje djelovanje. Zbog toga su sva stvorenja na razini djelovanja sastavljena, i to od vlastitog bivstvovanja i samog djelovanja, što implicira da su sastavljena od ontoloških supočela: supstancije i akcidenata.

Za razliku od toga, kad je riječ o naravi nužne sastavljenosti stvorenja na razini bivstvovanja, naši naučitelji imaju različita mišljenja. Tako Anđeoski naučitelj poima bitak kao akt bivstvovanja, koji je akt sve i svake zbilje bića jer svakom ,jest“, ukoliko jest, daje da bude. Nadalje, budući da stvorenja nemaju puninu bitka, što je vlastito samo Bogu, u stvorenjima je bitak nužno umanjenog intenziteta, ograničen na nekakav način bivstvovanja, što implicira da je u stvorenjima bitak nužno združen s bîti - potencijom koja ga ograničava na baš taj i takav način bivstvovanja (modus essendi). ${ }^{4}$ Dakle, prema svetom Tomi, sva su stvorenja na razini bivstvovanja nužno sastavljena, i to od bitka i bîti, tj. od akta bivstvovanja i potencije (modus essendi).

Za razliku od Tome, Serafski naučitelj zaključuje da sva stvorenja na razini bivstvovanja imaju nužno dvostruku sastavljenost, i to: od supozita i bîti i od entis et esse. Na prvu sastavljenost zaključuje iz činjenice da se bît, koja je zajednička individuama iste vrste, umnaža sa svakim partikularnim subjektom. ${ }^{5}$ Iz toga se neposredno izvodi da se u svakom individuu realno razlikuju njegova bît od

3 Usp. Bonaventura da Bagnoregio , 1 Sent, d. 8, p. 2,q. 2, concl., i također 2 Sent, d. 3, p. 1, a.1, q. 1; te Toma Akvinski, ST, I, q. 50, a. 2, ad. 3, i također ST, I, q. 54, a. 1 , co.

4 Usp. Hrvoje Relja, Tomistička filozofija. 1. dio, Filozofski fakultet Sveučilišta u Splitu, Split, 2013., 49.

5 Sveti Toma ne prihvaća samu premisu argumentacije, tj. da se u svakoj vrsti može dati veći broj individua, jer je mišljenja da su duhovna bića, tj. anđeli, nužno jedinstveni u svojoj vrsti, tj. svaki anđeo je cijela svoja vrsta. Razlika između sv. Tome i sv. Bonaventure o ovom pitanju imala je za posljedicu različitost njihovih pozicija oko dosega hilermofizma. Tako sv. Bonaventura zastupa univerzalni hilermofizam stvorenja kojim objašnjava mnoštvenost individua svih vrsta bića uključujući i ona duhovna, tj. anđele, dok su za svetog Tomu samo tjelesna bića hilermorfijski sastavljena pa se stoga samo među njima može dati više individua iste vrste. 
njegova supozita (in omni individuo differt essentia et suppositum). ${ }^{6}$ Na drugu sastavljenost zaključuje iz činjenice da svako stvorenje, ukoliko je stvoreno, nužno ima bitak po drugome, pa su stoga sva stvorenja sastavljena od entis et esse. Sv. Bonaventura objašnjava da ,je to razlikovanje [entis et esse] prisutno u svemu stvorenom i su-stvorenom, budući da sve što 'jest' izuzev Boga, prima esse izvana, bilo da je počelo ili sastavljeno od počela, dakle ništa nije svoj esse kao što svjetlo nije svoje svijetljenje“. ${ }^{7}$

Upravo je ovo posljednje razlikovanje entis et esse kod svetog Bonaventure bilo na različite načine interpretirano. Te interpretacije ovise dakako o načinu na koji se Bonaventuri pripisivalo shvaćanje bitka i bîti, pa time i naravi stvorenja na osnovnoj ontološkoj razini. Usredotočit ćemo se sada na te interpretacije i na njihov odnos prema tomističkom poimanju razlikovanja bitka i bîti u stvorenjima, odnosno na njihov odnos prema tomističkom poimanju bića na osnovnoj ontološkoj razini.

\section{BONAVENTURINA METAFIZIKA SUČELICE TOMISTIČKOJ METAFIZICI BITKA}

Različite interpretacije Bonaventurinog poimanja sastavljenosti entis et esse možemo svrstati u dvije osnovne skupine: prvu, u kojoj se negira postojanje realne razlike između bîti i bitka i u kojoj se distinkcija entis et esse interpretira kao umna razlika (distinctio rationis), a Bonaventurino esse shvaća kao počelo poistovjećeno $\mathrm{s}$ bîti $^{8}$ i drugu, u kojoj se distinkcija entis et esse interpretira kao realna razlika (distinctio realis) bîti i bitka. ${ }^{9}$ Budući da je Serafski naučitelj izričit da je razlika entis et esse izričaj jedne od triju nužnih sastavljenosti stvorenog bića, jedne na razini djelovanja i dviju na razini bivstvovanja, od komplementarnih metafizičkih počela - a

\footnotetext{
Bonaventura da Bagnoregio, 1 Sent, d. 8, p. 2, q. 2, concl.

Bonaventura da Bagnoregio, 1 Sent, d. 8, p. 2, q. 2, concl.

8 Usp. Robert P. Patrice, O. F. M, Hylemorphisme Et Devenir Chez Saint Bonaventure, Librairie Saint-François, Montreal, 1936.; Kurt Ziesché, Die Naturlehre Bonaventuras: nach den Quellen dargestellt, Fuldaer Actiendruckerei, Fulda, 1908.; George P. Klubertanz, Esse and Exsistere in St. Bonaventure, Mediæual Studies 8 (1946), 169-188.

9 Usp. Joseph Bittremieux, Distinctio inter essentiam et esse apud S. Bonaventuram, Ephemerides theologicae lovanienses 14 (1937), 302-307.; B. R. P., De Mente S. Bonaventurae et Alexandri Halensis circa Distinctionem Essentiae ab Existentia, Divus Thomas (Placentiae) 2 (1885); 525-555. Takvu se interpretaciju smatralo tradicionalnom te je kao takva prihvaćena i od urednika i komentatora u Opera Omnia S. Bonaventurae, Quaracchi (1882-1902), vol. 1, 169, scholion.
} 
što implicira njihovu realnu razliku (distinctio realis) ${ }^{10}$ - čini nam se da je prvu skupinu interpretacija plauzibilno držati neosnovanom. Stoga ćemo sada pokušati uvidjeti koja bi od interpretacija unutar druge skupine bila autentična.

Poteškoću za autentičnu interpretaciju predstavlja činjenica da sam Bonaventura nije jasno i nedvosmisleno objasnio značenje koje daje pojmu bitka (esse) te njegovog odnosa prema drugim zbiljnostima. ${ }^{11}$ Stoga ćemo pokušati na osnovi njegovih drugih eksplicitnih i nedvojbenih metafizičkih pozicija, univerzalnog hilemorfizma i pluraliteta supstancijalnih formi, deducirati njegovo poimanje bitka te tako razjasniti značenje distinkcije entis et esse.

a) Bonaventurino poimanje bitka $u$ svjetlu njegova univerzalnog hilemorfizma

Pobornici teze da sveti Bonaventura zastupa realnu sastavljenost bîti i bitka na način sv. Tome, tj. shvaćajući bitak kao akt bivstvovanja, koji je akt sve i svake zbilje bića, jer svakom ,jest“, ukoliko jest, daje da bude, a bît kao potenciju koja ograničava i određuje to ,jest“ na baš taj i takav način bivstvovanja, teško mogu objasniti inzistiranje Serafskog naučitelja na tezi da sva stvorenja nužno moraju biti sastavljena od materije i forme. Tu tezu sveti Bonaventura temelji na dvije činjenice: prvoj da su, za razliku od apsolutno jednostavnog Stvoritelja koji je Čisti akt, sva stvorenja sastavljena od potencije i akta, i to kako smo vidjeli na tri razine; te na drugoj da su sva stvorenja, za razliku od Boga koji je nepromjenjive bîti, promjenjiva te stoga imaju potencijalno počelo koje je subjekt promjene. Budući da iz tih dviju činjenica slijedi metafizička sastavljenost svih stvorenih bića od potencije i akta, Bonaventura tvrdi da je to objašnjivo samo pomoću sastavljenosti stvorenja od dva metafizička počela: materije i forme. ${ }^{12}$ Navedena pozicija Serafskog naučitelja upućuje na pretpostavku da bi bilo primjerenije shvatiti njegovo poimanje sastavljenosti entis et esse u svih stvorenih bića na način Avicene, tj. u svjetlu esencijalističke metafizike u kojoj se bît shvaća kao moguće, ali potpuno definirano biće, a postojanje kao njegov „akcident“ koje ništa ne daje samom sadržaju tog bića, a ne u

10 Usp. Bonaventura da Bagnoregio, 2 Sent, d. 3, p. 1, a. 1, q. 1, gdje se među ostalim navodi „Nadalje, [uočavamo sastavljenost bića] promatrajući biće u sebi, ukoliko je u svakom stvorenju njegovo zbiljsko esse sastavljeno od entis et esse (Item, habet considerari ut ens in se; et sic quantum ad esse actuale est in ipso compositio entis et esse)."

11 George P. Klubertanz, Esse and Exsistere in St. Bonaventure, 169-170.

12 Usp. Bonaventura da Bagnoregio, 2 Sent, d. 3, p. 1, a. 1, q. 1. 
svjetlu tomističke metafizike bitka koja ne zahtijeva sastavljenost od materije i forme.

Nadalje, budući da se u esencijalističkoj metafizici biće, ukoliko biće, poistovjećuje sa samom bîti, iz tog proizlazi da se zahtijevana nužna sastavljenost stvorenog bića od akta i potencije treba dati na razini same bîti, što podrazumijeva sastavljenost od materije i forme. Nasuprot tome, u tomističkoj metafizici bitka ne zahtijeva se sastavljenost od materije i forme jer se nužna sastavljenost stvorenja od akta i potencije objašnjava sastavljenošću od bîti - potencije (modus essendi) i bitka - akta (actus essendi), ${ }^{13}$ dok se nužna promjenjivost stvorenja objašnjava sastavljenošću od supstancije i akcidenata, gdje je supstancija, ukoliko nositelj bitka, subjekt promjene, a akcidenti, ukoliko nositelji daljnjeg određenja bitka, donositelji promjenjivosti.

b) Bonaventurino poimanje bitka $\mathrm{u}$ svjetlu njegova pluraliteta supstancijalnih formi

Pobornicima teze da Bonaventurino shvaćanje bitka proizlazi kao i kod sv. Tome iz metafizike bitka, a ne kao kod Avicene iz esencijalističke metafizike, sličnu poteškoću predstavlja i druga stožerna teza Bonaventurine metafizike, ona o mnoštvenosti supstancijalnih formi. Metafizički dosezi navedene pozicije najzornije se uočavaju u razlaganju Serafskog naučitelja o naravi duše i njenog odnosa s tijelom. Ljudska duša je, kako objašnjava, istinska, ali nedovršena supstancija. Po sebi je sastavljena od konkretne materije i konkretne forme te je stoga istinska supstancija, a budući da je konstitutivno naravi duše, pa i kada je odvojena od tijela, da teži oformiti konkretno tijelo, ona sama, tj. duša po sebi, nije potpuno dovršeno cjelovito biće (ens completum). ${ }^{14}$ Dakle, zaključuje Bonaventura, duša je po sebi bez ujedinjenja s tijelom priopćiva supstancija, tj. ne baštini nepriopćivost vlastitu dovršenoj supstanciji. ${ }^{15}$ Navedena pozicija o ujedinjenju duše i tijela - dviju istinskih supstancija koje zadržavaju, ukoliko istinske supstancije, svoje supstancijalne forme - $\mathrm{u}$ jedno

13 Usp. Toma Akvinski, ST, I, q. 50, a. 2, ad 3.

14 Usp. Bonaventura da Bagnoregio, 2 Sent, d. 17, a. 1, q. 2, ad. 6.

15 Usp. Bonaventura da Bagnoregio, 3 Sent, d. 5, a. 2, q. 3, r.; za cjeloviti prikaz Bonaventurinog poimanja individualnosti i nepriopćivosti vidi Peter King, Bonaventure's Theory of Individuation. U: Jorge J. E. Gracia, Individuation and Scholasticism: The Later Middle Ages and the Counter-Reformation 115-1650 (str. 141-172), State University of New York Press, New York, 1994.; gdje na 5 str. ističe da „Individuality need not entail incommunicability; Bonaventure specifically describes the separated human soul as singular, and hence individual, but as communicable since it is apt to be united with a body as an essential feature." 
cjelovito biće, tj. dovršenu supstanciju (čovjeka), u kojem je jedna od supstancija (duša) forma cjeline, upućuje da se Bonaventurino poimanje sastavljenosti entis et esse u svih stvorenih bića interpretira na način Avicene. Po tomističkom shvaćanju bitak je radikalni akt koji aktualizira svaki akt u supstanciji (actualitas omnium actuum) ${ }^{16}$ i u svakoj supstanciji je nužno jedan, a njegovo ograničenje proizlazi iz bîti same supstancije koja ga ograničava na upravo takav jedan jedinistveni konkretan način bistvovanja (modus essendi). Prema tome, tomisti zastupaju samo jedno aktivno počelo u kategorijalnom redu, a to je supstancijalna forma. Drugim riječima, po tomističkoj metafizici bitka jedan akt bivstvovanja (esse) primljen i ograničen od jedne potencije (bîti) formira samo jednu novu aktualnost (supstancijalnu formu). ${ }^{17}$ Dakle, budući da tomističko poimanje bitka isključuje mnoštvenost supstancijalnih formi u konkretnoj supstanciji, primjerenije je prihvatiti da Serafski naučitelj pretpostavlja Avicenino shvaćanje bitka kao „akcidenta“ mogućeg bića (bîti); te da se slijedom takvog shvaćanja različite supstancijalne forme združuju u jedno jedinstveno zajedničko postojanje posredstvom jednog im zajedničkog „akcidenta“ - bitka. Na taj se način u novoj jednoj jedinstvenoj supstanciji zadržavaju sve vlastite aktualnosti različitih supstancijalnih formi bića, a njihovo novo jedinstveno postojanje zahvaljuju jednom jedinom zajedničkom im bitku.

\section{Poimanje BitKa u BonaVEntuRinoJ ESENCIJALISTIČKOJ METAFIZICI}

Navedena interpretacija poimanja sastavljenosti entis et esse svrstava Bonaventuru u zbor esencijalističkih metafizičara, i to u isti dio zbora, glas, u kojem je i Avicenna, s kojim dijeli uvjerenje da se moguće biće (bît) i stvarno biće (konkretna bît) razlikuju samo u „akcidentu“ postojanja, ali zbog različitog shvaćanja tog „akcidenta" postojanja zauzimaju ipak suprotne pozicije unutar istoga glasa. Pobliže, budući da je za Avicennu čin postojanja nužni stvoriteljski čin Nužnog bića po kojemu sve što jest nužno jest, Avicenna shvaća postojanje kao akcident koji nužno prati konačnu bît, tj. kao akcidentalnu vlastitost stvarne bîti, a ne kao čin njena postojanja. Kako

16 Toma Akvinski, De pot, q. 7, a. 2, ad. 9.

17 Uočimo da slijedom tomističke metafizike negiranje mnoštvenosti supstancijalnih formi može biti argumentirano dedukcijom iz temeljnih metafizičkih počela bića - bîti i bitka - a ne samo ukazujući da bi pretpostavljena mnoštvenost supstancijalnih formi implicirala pluralitet supstancija, jer supstancijalna forma, ukoliko je zadnja zbiljnost u kategorijalnom redu, određuje supstanciju kao supstanciju. 
primjećuje Gilson: „Postojanje avicennijanskog mogućeg [bîti] nije čin postojanja zahvaljujući kojemu to moguće postoji, već je to sâmo to moguće [bît] što ga njegov uzrok čini postojećim." 18 Dok Bonaventurino poimanje sastavljenosti entis et esse držimo plauzibilnim shvatiti kao sastavljenost na transcedentalnoj razini dvaju realno različitih počela: bîti, potpuno definiranog/određenog/individualnog mogućeg bića, i bitka, čina postojanja realnog konkretnog bića. Navedena se distinkcija temelji na Bonaventurinom razlikovanju bivstvovanja (esse) i postojanja (exsistens). ${ }^{19}$ Da pojasnimo, Serafski naučitelj poima „bivstvovanje (esse) kao poopćivanje postojanja (exsistens); i to na način da se jedino za zbiljsko biće može reći da postoji (exsistit), dok se za moguće biće može reći da bivstvuje (est), tako se neko moguće biće - kao što je npr. Sokratov brat blizanac može ispravno okarakterizirati kao individuum “. ${ }^{20}$ Drugim riječima „postojanje (exsistens) je za sv. Bonaventuru tehnički termin za esse hoc ${ }^{21}{ }^{21}$ Navedena je distinkcija vidljiva iz Bonaventura objašnjenja postojanja Kristove ljudske naravi: za Krista se treba reći da je samo jedan supozit jer ima samo jedno jedino postojanje (exsistens); uz to mu se također treba pripisati ne samo da ima dvije naravi, već da ima dvije stvari od dviju naravi (res naturae), tj. da je Krist kao čovjek (res naturae) potpuno određen u svome biti čovjek neovisno o svom postojanju. ${ }^{22}$ Drugim riječima, konkretna Kristova ljudska narav (res naturae) ima svoje određeno bivstvovanje (esse) neovisno o svom postojanju (exsistens) koje ima ili nema u supozitu Riječi. ${ }^{23}$ Dakle, kako su, prema Serafskom naučitelju, isključivo ovisno o načinu na koji se ostvaruje konkretno postojanje (exsistens) Kristove ljudske naravi, teoretski moguća dva stvarna bića, tj. supozita - ono koje se stvarno ostvarilo i koje ima postojanje u supozitu Riječi te ono koji se nije ostvarilo, a koje bi moglo imati postojanje u vlastitom

18 Étienne Gilson, Bitak i bit, 130.

19 O Bonaventurinu razlikovanju bivstvovanja (esse) i postojanja (exsistens) vidi George P. Klubertanz, Esse and Exsistere in St. Bonaventure; te Peter King, Bonaventure's Theory of Individuation, gdje autori analizom Bonaventurinih tekstova nepobitno ukazuju na postojanje navedene distinkcije.

20 Peter King, Bonaventure's Theory of Individuation, 3.

21 George P. Klubertanz, Esse and Exsistere in St. Bonaventure, 187.

22 Usp. Bonaventura da Bagnoregio, 3 Sent, d. 6, a. 1, q. 1, r.

23 U tomističkoj metafizici u kojoj je, kao što smo vidjeli, bitak akt bivstvovanja po kome svaka zbilja stvari/bića ,jest“, nije prihvatljivo postojanje res nature koje bi se razlikovalo od supozita te naravi (usp. Toma Akvinski, 3 Sent, d. 6, q. 1, a. 1, qc. 4, s. c. 1). Navedeno je još jedan argument da Bonaventura ne shvaća bitak na tomistički način. 
supozitu $^{24}$ - te kako je nužno da svako razlikovanje stvarnih bića, supozita, proizlazi iz različitosti njima nutarnjih ontoloških počela, potrebno je zaključiti da je za Bonaventuru postojanje (exsistens) nešto što pripada ostvarenom biću kao njegovo nutarnje počelo, i to počelo po kojem supozit biva ostvaren. Navedeno upućuje da Serafski naučitelj postojanje shvaća kao čin, ali ne kao čin bivstvovanja, tj. sveobuhvatni akt bića, nego kao akt postojanja već sveobuhvatno aktualiziranog bića, a što je za njega sama bît.

Ovakva interpretacija Bonaventurina shvaćanja sastavljenosti entis et esse otvara novo važno metafizičko pitanje: ${ }^{25}$ na koji je načina moguće argumentirati, te je li prihvatljivo da bitak/postojanje bude samo i isključivo akt postojanja, a da istovremeno ne bude akt bivstvovanja, tj. da bude akt koji daje samo postojanje bez ikakva drugog sadržaja. Budući da je navedena pozicija Bonaventurin metafizički pokušaj objašnjenja stvorenosti stvorenja, tj. poimanje ontološke strukture stvorenja i njegovog odnosa sa Stvoriteljem na način da se izbjegnu bilo kakve panteističke, emanacijonističke i monističke pozicije, i to u svjetlu esencijalističke metafizike, navedena pozicija se argumentira kao metafizička dedukcija stvaranja u pretpostavci esencijalističke metafizike. Uz to samo u esencijalističkoj metafizici je pojmljivo i prihvatljivo poimanje bitka kao akta postojanja koji ne daje nijedan drugi sadržaj, tj. nikakvo bivstvovanje već isključivo postojanje bivstvujućeg bića/bîti, dok bi jedno takvo poimanje bitka u svjetlu tomističke metafizike bitka bilo apsurdno jer je u njoj postojanje vlastitost samog bitka; stoga je za tomiste nezamislivo bivstvovanje bez postojanja i postojanje bez bivstvovanja.

\section{ZAKLJUČAK}

Zaključno možemo kazati da je Bonaventura, kao i uostalom svi kršćanski filozofi, adoptirao pojam bitka kako bi na ontološkoj razini objasnio stvorenost stvorenja jer se metafizički uviđa da svako stvoreno biće, ukoliko je stvoreno, nužno prima svoj bitak od Stvorite-

24 Primijetimo da su po tomističkoj metafizici, prema kojoj postojanje nije drugo doli jedna od vlastitost bivstvovanja, također teoretski moguća dva supozita Kristove ljudske naravi i to onaj koji se stvarno ostvario, koji bivstvuje bitkom Riječi te onaj mogući koji bi bivstvovao vlastitim bitkom i imao vlastitu osobnost (Usp. Toma Akvinski, ST, III, q. 2, a. 2 i 3).

25 Navedena interpretacija Bonaventurinog shvaćanja sastavljenosti entis et esse otvara također i važno povijesno filozofsko pitanje. Budući da njegova razrada izlazi iz okvira ovog rada, samo ga navodimo: kakav je utjecaj imalo Bonaventurino poimanje sastavljenosti entis et esse na Scotovu esencijalističku metafiziku i na njegovo poimanje modusa bivstvovanja. 
lja. Stoga se iz same stvorenosti stvorenja zahtijeva da na osnovnoj ontološkoj razini stvoreno biće bude metafizički sastavljeno od bitka i njemu komplementarnog počela, a što Serafski naučitelj formulira kao sastavljenost od entis et esse. Iako sam Bonaventura ne daje pobliže tumačenje naravi te sastavljenosti, ipak se dade deducirati iz njegovih osnovnih filozofskih i teoloških teza, koje pretpostavljaju prethodno pojmljenu osnovnu ontološku strukturu bića, da je se ne može shvatiti na način tomističke metafizike bitka, već da je plauzibilno shvatiti sastavljenosti entis et esse kao sastavljenost na transcedentalnoj razini dvaju realno različitih počela: bîti, potpuno definiranog/određenog/individualnog mogućeg bića, i bitka, čina postojanja realnog konkretnog bića.

\section{THE SIGNIFICANCE OF BONAVENTURE'S DISTINCTION BETWEEN ENTIS ET ESSE}

\section{Summary}

This paper shows how St. Bonaventure, as all other Christian philosophers, adopted the notion of existence in order to explain, on the ontological level, the property of being created that belongs to all creatures, since it is metaphysically realized that every creature, in so far as created, necessarily acquires its existence from the Creator. Consequently, that fact requires that, on the basic ontological level, the creature is metaphysically composed out of existence and a principle complementary to it, which is what the Seraphic Doctor formulates as the composition out of entis et esse. Although Bonaventure himself does not give a precise interpretation of the nature of the aforementioned composition out of entis et esse, it can be, as it is shown in the paper, deduced from his fundamental philosophical and theological theses, which presuppose a previously delineated basic ontological structure of being. Following that deduction, one can infer that Bonaventure's composition out of entis et esse cannot be interpreted in the perspective of the Thomistic metaphysics of existence, but that it should be understood in the light of an essentialist metaphysics, more precisely as the composition on the transcendental level out of two distinct principles: essence, that is, a fully defined/determined/individual possible being, and existence, concrete being's act of existing.

Keywords: entis et esse, St. Bonaventure, existence, essentialist metaphysics 